\section{$\underset{\substack{\text { hommes } \\ \text { \& migrations }}}{ }$}

\section{Hommes \& migrations}

Revue française de référence sur les dynamiques

migratoires

\section{$1308 \mid 2014$}

Les Paris des migrants

\title{
Entre horreur et espérance
}

Billet d'humeur du comité de rédaction de la revue

\section{(2) OpenEdition}

Journals

\section{Édition électronique}

URL : http://journals.openedition.org/hommesmigrations/3052

DOI : 10.4000/hommesmigrations.3052

ISSN : 2262-3353

Éditeur

Musée national de l'histoire de l'immigration

Édition imprimée

Date de publication : 1 octobre 2014

Pagination : 4-5

ISBN : 978-2-919040-29-2

ISSN : 1142-852X

Référence électronique

«Entre horreur et espérance », Hommes \& migrations [En ligne], 1308| 2014, mis en ligne le 01 octobre 2017, consulté le 24 septembre 2020. URL : http://journals.openedition.org/hommesmigrations/3052 ; DOI : https://doi.org/10.4000/hommesmigrations.3052 


\section{ENTRE HORREUR ET ESPÉRANCE}

par le COMITÉ DE RÉDACTION

I est difficile pour une revue de sciences sociales de ne pas réagir à chaud aux tueries de ce début janvier 2015, aux atteintes portées aux valeurs et aux symboles qui se rattachent aux personnes assassinées. Ce texte exprime notre attachement indéfectible à la liberté d'expression, au respect de la diversité, et à la laïcité qui en permet l'expression. Il annonce aussi les orientations d'une réflexion approfondie sur les différents volets mis en lumière ces derniers jours. Un dossier thématique interrogera, sur la base de travaux bien délimités, les institutions (école, police, prison, etc.), les dynamiques sociales (situations migratoires, engagement religieux,etc.) et l'espace politique.

La France a vécu une série d'attentats meurtriers contre Charlie Hebdo et l'Hyper Cacher de la Porte de Vincennes qui ne peuvent manquer d'interroger une revue comme la nôtre. Nous exprimons d'abord notre horreur devant les lâches attentats commis au nom d'une idéologie qui ne peut être cautionnée en aucune manière par toute personne attachée à la démocratie et à la liberté d'expression. Nous exprimons notre soutien aux familles de toutes les victimes et à Charlie Hebdo qui, à sa manière irrévérencieuse, ne fait jamais que dénoncer le sectarisme et le fanatisme de toute provenance dont les chercheurs ont pu mesurer les effets négatifs en termes de cohésion sociale, de cohabitation entre les cultures et de relations sociales sur les terrains qu'ils ont étudiés. Déjà en 2011, la revue s'était affirmée "aux côtés de Charlie Hebdo" suite à l'attentat au cocktail Molotov qui avait dévasté les locaux du journal dans la nuit du $1^{\text {er }}$ au 2 novembre et avait publié des dessins de Charb réalisés à cette occasion.
En ces temps de confusion attisée par divers prêcheurs en eaux troubles, il nous paraît nécessaire de préciser que la manière satirique dont un journal, marqué par une culture libertaire, stigmatise les dérives totalitaires de ceux qui prétendent parler au nom de l'islam n'a rien à voir avec les appels à la haine communautaire que l'on peut entendre ici ou là. La liberté d'expression ne peut se négocier, comme l'ont affirmé courageusement nombre d'intellectuels du monde musulman qui savent plus que nous le prix de cet attachement. Ainsi Elham Manea, militante yéménite, explique pourquoi elle a publié sur son site deux caricatures de Mahomet parues dans Charlie Hebdo: "Pourquoi, est-ce que je l'ai fait? Non pas pour insulter quiconque ni pour inciter à la haine. Je suis et reste déterminée à me situer à l'intérieur de l'islam, la religion que j'ai choisie. Si je l'ai fait, c'est pour rappeler que la liberté d'expression n'est pas négociable. C'est un droit de l'homme qui doit être respecté même si ce qui s'exprime nous heurte ou nous blesse."

C'est pour défendre cet acquis que des millions de Français de toutes origines et confessions se sont rassemblés, apportant ainsi la meilleure réponse possible à cette tentative de division espérée par les manipulateurs qui ont guidé ces attentats. Cette maturité politique est un précieux démenti aux affirmations de ceux qui pensent que le consommateur a effacé depuis longtemps le citoyen et que l'appartenance communautaire a supplanté l'adhésion républicaine. Les mobilisations et solidarités internationales qui se sont exprimées à cette occasion démontrent aussi que la France reste perçue comme un pays qui ne transige pas avec la défense des libertés fondamentales et des droits de l'homme. Il serait bien sûr angélique 
d'imaginer que ce moment privilégié d'unité nationale s'inscrive durablement dans le temps et résolve les multiples contradictions qui minent la société française. Même si la majorité des populations qui vivent aujourd'hui dans les cités et autres banlieues sont à l'unisson du reste de la communauté nationale. Même si depuis presque deux générations, mille et une initiatives, actes de solidarité ou de création tentent de maintenir le vivre-ensemble. Il serait certainement utile d'interroger les politiques publiques menées par l'État ou les collectivités territoriales depuis plusieurs décennies pour soutenir ou non ces actions citoyennes sur ces territoires-là.

"Ne pas faire l'amalgame" : tel fut le maître mot consécutif aux massacres des 7, 8 et 9 janvier derniers. Avec raison, car confondre islam, terrorisme et descendants de migrants eût instantanément suscité haine raciale et guerre de religions. Pour comprendre comment de jeunes Français ont pu arriver à un tel degré de haine contre les valeurs du pays dans lequel ils ont été éduqués, la revue se doit à l'avenir d'ouvrir des chantiers de réflexion sans doute quelque peu négligés. Tout d'abord, dans le monde globalisé qui est aujourd'hui le nôtre, on ne peut ignorer les processus de mobilité et les dynamiques de propagation des ressentis liés à des événements qui se produisent à distance. L'image des jeunes qui "rouillent" aux murs de leurs cités ne cachet-elle pas leur sensibilité à ce qui se passe au niveau planétaire et leur identification à des combats qui s'expriment loin de chez eux ? Leur quête de sens provoquée par le sentiment d'une absence d'avenir vu teur condition sociale actuelle n'entraîne-t-elle pas l'adhésion à des causes contraires aux valeurs du pays dont ils sont pourtant citoyens ? Le message républicain délivré par l'école ne perd-il pas de sa portée quand il n'est plus associé à l'espoir d'une amélioration de sa condition? Les frustrations dans une société qui exalte la réussite matérielle aux dépens de tout autre idéal ne génèrent-elles pas inévitablement une culture du ressentiment chez ceux qui se perçoivent comme condamnés à une précarité transgénérationnelle ? L'habitude de contourner des lois perçues comme totalement extérieures n'aboutit-elle pas, dans des cas extrêmes, à oublier des valeurs aussi fondamentales que le respect de la vie humaine? Toutes ces questions bousculent nos certitudes sur ces jeunes générations et doivent être revisitées.

La laïcité, socle du vivre-ensemble, est mal comprise. En son nom, on doit bien sûr défendre la liberté d'expression mais condamner aussi les actes malveillants contre les lieux de culte et contre les pratiquants de toutes religions. La problématique du religieux et des religions dans la France laïque du XIXe siècle est un des chantiers de connaissances et de réflexion important pour la revue. Internet et les réseaux sociaux ont ouvert de nouvelles perspectives en matière de socialisation d'une population très familiarisée avec les nouvelles technologies de la communication. Il y a là tout un domaine de recherche sur les processus de radicalisation qui ne passent plus par la fréquentation de groupes extrémistes mais par l'accès en quelques clics à la parole de maîtres à penser. Ces derniers sont d'autant plus convaincants qu'ils sont invisibles et qu'ils reçoivent sans discussion et sans remise en cause le renfort de milliers d'adeptes anonymes.

Après l'onde de choc provoquée par ces attentats, comment nier que le lien entre les manifestations critiques dans le monde musulman et les réactions contradictoires de jeunes en milieu scolaire en France, concerne plus que quelques illuminés ultraviolents ? Cette relation historique entre les populations se réclamant de l'islam et les sociétés dans lesquelles elles sont insérées apparaît aujourd'hui asymétrique. La relation migratoire - après le rapport colonial dans le passé est une des traductions de cette asymétrie. C'est aussi un moyen de la résoudre. Car les liens transnationaux construits entre les sociétés permettent la circulation de bien des valeurs, non seulement idéologiques mais aussi sociales et économiques, en même temps que culturelles et intellectuelles. C'est dans cet échange entre les pôles de la mobilité, dans cette relation entre migrations et développements, que s'ébauchent des expressions partagées - et non imposées - de la mondialisation. Le problème dépasse largement le cas français, même si nos banlieues en sont une criante traduction locale. C'est pourquoi, au-delà du premier sursaut de l'identité nationale, il faut travailler maintenant également sur des options cosmopolitiques. 